\title{
Low neutrophil-to-Imphocyte ratio decreases risk of coronavirus disease in pregnant women
}

\author{
Nutria Widya Purna Anggraini* and Sri Sulistyowati**
}

\begin{abstract}
*Department of Obstetrics and Gynecology,

Faculty of Medicine,

Universitas Sebelas Maret/

RS Dr. Moewardi Hospital, Surakarta

**Department of Obstetrics and

Gynecology,

Faculty of Medicine,

Universitas Sebelas Maret/

RS Universitas Sebelas Maret,

Surakarta

\section{BACKGROUND}

Coronavirus Infection 2019 (COVID-19), caused by the severe acute respiratory syndrome coronavirus 2 (SARS-CoV-2), is an emergency condition for global public health. Early detection of COVID-19 in pregnant women is needed. The neutrophil-to-lymphocyte ratio (NLR), as a marker of viral inflammatory response, is used to determine the presence of a viral or bacterial infection, both acute and chronic. The objective of this study was to determine the relationship between NLR and the polymerase chain reaction (PCR) swab test results in pregnant women with suspected coronavirus disease 2019.
\end{abstract}

Correspondence:

dr. Nutria Widya Purna Anggraini,

Sp.OG(K), M.Kes

Department of Obstetrics and

Gynecology

RSUD Dr. Moewardi

Jl. Kol. Sutarto 132 Surakarta

Phone: +62271 665145

E-mail: nutria_dr@staff.uns.ac.id

ORCID ID: 0000-0001-7652-1038

Date of first submission, May 31, 2020 Date of final revised submission, July 4, 2020

Date of acceptance, July 7, 2020

This open access article is distributed under a Creative Commons AttributionNon Commercial-Share Alike 4.0 International License

Cite this article as: Anggraini NWP, Sulistyowati S. Low neutrophil-tolmphocyte ratio decreases risk of coronavirus disease in pregnant women. Univ Med 2020;39:88-96. doi: 10.18051/UnivMed.2020.v39.88-96

\section{METHODS}

A cross-sectional study was conducted on 9 pregnant women with suspected COVID-19. The subjects were inpatients at Moewardi Hospital Surakarta from 19 April-19 May 2020, who had rapid tests, complete blood examinations, and PCR swab tests. The NLR was categorized based on early warning scores according to research developed at Zhejiang University, with cut-off point 5.8. Diagnosis of COVID-19 was confirmed by PCR swab tests. Relation between NLR and PCR swab results was analyzed by the prevalence ratio.

\section{RESULTS}

Two patients $(22.2 \%)$ had NLR $\geq 5.8$, with positive swab results in both $(100 \%)$. Seven patients with NLR $<5.8$ had positive swabs in only one (33.3\%). The relationship between NLR and PCR swab test results showed a prevalence ratio of $0.143(95 \% \mathrm{CI} 0.023-0.877)$.

\section{CONCLUSION}

Pregnant women with NLR $<5.8$ had a decreased risk of COVID-19. Routine blood examination is more suitable for finding pregnant women with suspected COVID-19.

Keywords: Neutrophil-to-lymphocyte ratio, PCR swab, COVID-19, pregnancy 


\section{INTRODUCTION}

Coronavirus disease 2019 (COVID-19) is caused by the severe acute respiratory syndrome coronavirus 2 (SARS-CoV-2) and emerged initially in Wuhan, China, in December 2019. Currently the COVID-19 infection is a public health emergency, particularly in susceptible populations. ${ }^{(1)}$ Pregnant women and their fetuses constitute a susceptible and high risk population, due to the physiological and mechanical factors in pregnancy that increase the susceptibility to infections in general, particularly in the cardiorespiratory system, and trigger the occurrence of respiratory failure. ${ }^{(2)}$ During the COVID-19 epidemic pregnant women apparently have fewer maternal and neonatal complications than has been reported for SARS and MERS. ${ }^{(3)}$ There were more than 193.000 deaths (up to 24 April 2020), but no reports of maternal deaths were published. In China a total of 154 pregnant women have been reported with maternal morbidity of $1 \%$ and no maternal deaths. In the US, there was $4-10 \%$ maternal morbidity and no maternal deaths. ${ }^{(4)}$

Pregnant women develop special immunological adaptations that are necessary to maintain semi-allograft tolerance to their fetuses. ${ }^{(5)}$ This repressed immunity is modulated by repressed $\mathrm{T}$ cell activity, where in pregnancy there is dominance of the T-helper 2 (Th2) system that protects the fetus, thereby rendering the mother susceptible to viral infections. ${ }^{(5)}$

Coronavirus disease 2019 infection is associated with cytokine storms that are marked by increased concentrations of plasma interleukin-2 (IL-2), IL-7, IL-10, granulocyte colony stimulating factor, interferon- $\gamma$-induced protein-10, monocyte chemoattractant protein-1, macrophage inflammatory protein-1 alpha, and tumor necrosis factor alpha $(\mathrm{TNF}-\alpha){ }^{(6)}$ Pregnant women in the first and third trimesters are in a proinflammatory condition, such that the cytokine storms induced by SARS-CoV-2 may cause more severe inflammation in these women. ${ }^{(7)}$ Based on all of the above, an integrated approach is needed, especially for early detection, prediction and evaluation of COVID-19 in pregnant women, both with respect to prevention, breaking of the transmission chain, and establishing the diagnosis as well as management, which are essential for improving the prognosis in pregnant women. ${ }^{(8)}$

The early detection of COVID-19 in pregnant women that is recommended by the Indonesian Obstetrics and Gynecology Association (Persatuan Obstetri and Ginekologi Indonesia, POGI), uses the early warning score (EWS) developed by the Zhejiang University. This comprises a number of parameters that are rather frequently found in patients with COVID-19, namely signs of pneumonia on CT scan, history of contact with COVID-19 positive patients, fever, temperature $>37.8^{\circ} \mathrm{C}$ from onset of symptoms, male gender, age $>40$ years, a number of symptoms of respiratory distress and a neutrophil-tolymphocyte ratio (NLR) of $\geq 5.8 .{ }^{(9)}$ Currently the early warning score is much in use and is a relatively accurate tool for early detection. ${ }^{(10)}$ The neutrophil-to-lymphocyte ratio is a component of the EWS, as marker of inflammatory reaction, and is an indicator of the complications associated with pregnancy. ${ }^{(8,11)}$

The inflammatory reaction in pregnant women plays an important role in a number of complications of pregnancy and is a strong contributor to mortality and morbidity in pregnant women. Therefore, inflammatory markers may be used both as predictors and prognostic factors. The neutrophil-to-lymphocyte ratio has been used as predictor of the complications of pregnancy, such as preeclampsia, gestational diabetes mellitus, hyperemesis gravidarum, premature labor and ectopic pregnancy ${ }^{(8)} \mathrm{A}$ high neutrophil-tolymphocyte ratio results from an increased number of neutrophils and a decreased number of lymphocytes. The inflammatory response stimulates the production of neutrophils and accelerates apoptosis of lymphocytes. Poor immune responses and immunological abnormalities are believed to influence disease severity triggered by viral infections. ${ }^{(12)}$ 
Repression of the immune response it results in an excessive inflammatory reaction and even death. Similar to the Midlle East respiratory syndrome coronavirus (MERS-CoV), the leukocyte differential count is the most outstanding predictor associated with disease severity. ${ }^{(13)}$ The differential count is characterized by increased neutrophils and monocytes and by decreased lymphocytes, which is found in all deceased patients. Studies on COVID-19 have shown that cytokine and chemokine concentrations and NLR values are higher in patients with COVID-19 and are associated with disease severity. ${ }^{(14,15)}$ In addition, patients with severe viral infection may have bacterial coinfection due to low immunity, resulting in increased NLR, C-reactive protein and procalcitonin. ${ }^{(16)}$ Currently the NLR constitutes a new strong inflammatory marker for the detection of inflammation. ${ }^{(17)}$ The NLR is more superior to the total leukocyte count, the neutrophil count, or the lymphocyte count as an inflammatory marker, because it is less influenced by a number of physiological conditions, such as dehydration or physical activity. Moreover, the NLR examination has advantages as compared with other inflammatory markers, such as CRP or interleukin, as it is easy to perform and is inexpensive. ${ }^{(14)}$ The neutrophil-to-lymphocyte ratio can be rapidly calculated from routine complete blood examination, so that the physician may identify patients at high risk for COVID-19 at an early stage. In COVID-19 infection, the numbers of leukocytes, lymphocytes, monocytes and platelets are lower than in the non-COVID19 group. The neutrophil-to-lymphocyte ratio is significantly higher in the COVID-19 group. The increased NLR in patients with COVID-19 is associated with disease severity. ${ }^{(15)}$

The diagnosis of COVID-19 depends mainly on the detection of SARS-CoV-2 nucleic acids through the polymerase chain reaction (PCR) swab test. However, there are still many limitations with the occurrence of false negative results caused by a low viral load in the sample and the relative shortage of detection kits, so that many cases remain undetected. ${ }^{(9)}$ There is a need for a method capable of rapid and early detection of COVID -19 in pregnant women, that may be used as predictor for preventing maternal morbidity and mortality.

A Chinese study involving 55 pregnant women (13 pregnant women with COVID-19 infection and 42 controls) showed no significant differences in NLR between the two groups, both during hospitalization and post-partum. ${ }^{(18)}$ However, these results differ from those of a Spanish study involving 60 pregnant women with COVID-19 infection and showing increased NLR in pregnant women with COVID-19 infection. ${ }^{(19)}$ These still inconsistent study results point to the need for further studies. In the COVID-19 pandemic the prevention and control of COVID19 infection in pregnant women is of utmost importance, particularly in the screening of pregnant women who are hospitalized for purposes of delivery. The present study aimed to determine any relationship between NLR and COVID-19 PCR swab test results in pregnant women suspected of suffering from COVID-19.

\section{METHODS}

\section{Design of the study}

This study was an observational analytic study of cross-sectional approach that involved as subjects pregnant women hospitalized in $\mathrm{Dr}$ Moewardi Hospital, Surakarta, which is the central referral hospital for the management of pregnant women with COVID-19. This study was conducted on nine pregnant women with COVID-19 hospitalized in RS Dr. Moewardi Hospital, Surakarta, from 19 April 2020 until 19 May 2020.

\section{Study subjects}

The study subjects were pregnant women hospitalized with the status of patients under supervision (pasien dalam pengawasan, PDP) for COVID-19. The inclusion criteria were pregnant women with signs and symptoms indicative of COVID-19, in accordance with the 
early warning score (EWS) of cough, rhinitis, fever, dyspnea, a picture of pneumonia, having previous contacts, and reactive rapid test results. The exclusion criteria were patients with a history of previous infections and non-reactive rapid test results.

\section{Diagnostic procedures}

The diagnosis of COVID-19 was based on the Guideline for Prevention and Control of Coronavirus Disease (COVID-19) by the Directorate General of Disease Prevention and Control, Republic of Indonesia. ${ }^{(10)}$ All subjects underwent complete blood examinations, chest $\mathrm{X}$-rays, and PCR swab tests.

\section{Data measurements}

The NLR is a systemic inflammatory marker in infectious disease obtained by dividing the absolute neutrophil count by the absolute lymphocyte count. The NLR is categorized into two groups with cut-off point of 5.8, namely group I at $\leq 5.8$ and group II at $\geq 5.8$, in accordance with the early warning score (EWS) based on the study developed at the Zhejiang University. ${ }^{(9)}$

The COVID-19 PCR swab test is a laboratory test for the detection of the SARS CoV2 virus using the rapid molecular test based on the PCR. Samples were swabbed from the oral and nasal cavities and were used to confirm cases of COVID-19 based on the detection of unique viral RNA sequences. The real-time reversetranscription polymerase chain reaction (rRTPCR) swab results were confirmed if necessary by nucleic acid sequencing. This examination was performed in the Clinical Pathology Laboratory, Dr. Moewardi Hospital, Surakarta. The results were categorized into two groups, namely group 1 with the criterion of positive results and group 2 with the criterion of negative results.

\section{Statistical analysis}

The collected data were analyzed using the SPSS program. Subsequently an association was looked for between NLR values and PCR swab results, using the chi square test. The association between NLR and COVID-19 in pregnant women was determined by means of the prevalence ratio.

\section{Ethical clearance}

Ethical clearance was obtained from the Health Research Ethics Committee, Dr. Moewardi Hospital/Faculty of Medicine, Universitas Sebelas Maret, Surakarta, Central Java, Indonesia under no. 755/VI/HREC/2020.

\section{RESULTS}

The results of this study may be seen in Table 1 on characteristics of pregnant women with COVID-19 infection.

Table 1 shows that the nine pregnant women were all in the third trimester, with eight patients undergoing cesarean section, and one patient undergoing conservative maintenance of the pregnancy at gestational age of 31 weeks. Maintenance of the pregnancy was done because it was still preterm and there were no signs of labor. The age range of the patients was 23-37 years and the gestational age range on admission was 31-42 weeks.

Two of the eight patients experienced fever but no chills, and none experienced high fever (body temperature $>39^{\circ} \mathrm{C}$ ). The body temperature of the patients fluctuated within the range of $36.5-38.8^{\circ} \mathrm{C}$. There were no patients with postpartum fever. Other symptoms of upper respiratory tract infection in two patients were cough accompanied with dyspnea. One patient was under mechanical ventilation during care. Another patient had pulmonary edema as complication, but not one of the nine patients experienced severe pneumonia or died of COVID-19 pneumonia up to May 2020.

There was a significant association between NLR and COVID-19 infection (prevalence ratio $=0.143 ; 95 \% \mathrm{CI}=0.023-0.877)($ Table 2$)$. This signifies that pregnant women with NLR $<5.8$ have a 0.143 times lower risk for having COVID19 infection than do pregnant women with NLR $\geq 5.8$. 
Table 1. Demographic characteristics and clinical manifestations in pregnant women $(n=9)$

\begin{tabular}{|c|c|c|}
\hline Variable & n $(\%)$ & Mean \\
\hline \multicolumn{3}{|l|}{ Age (years) } \\
\hline $20-34$ & $7(77.8)$ & $28.44 \pm 4.95$ \\
\hline$\geq 35$ & $2(22.2)$ & \\
\hline \multicolumn{3}{|c|}{ Gestational age (weeks) } \\
\hline$<37$ & $3(33.3)$ & \\
\hline $37-40$ & $4(44.4)$ & \\
\hline$>40$ & $2(22.2)$ & \\
\hline \multicolumn{3}{|l|}{ Parity } \\
\hline Primigravida & $4(44.4)$ & \\
\hline Multigravida & $5(56.6)$ & \\
\hline \multicolumn{3}{|l|}{ Contact history } \\
\hline Yes & $1(11.1)$ & \\
\hline No & $8(88.9)$ & \\
\hline \multicolumn{3}{|c|}{ Severe preeclampsia } \\
\hline Yes & $1(11.1)$ & \\
\hline No & $8(88.9)$ & \\
\hline \multicolumn{3}{|l|}{ Hypertension } \\
\hline Yes & $0(0.0)$ & \\
\hline No & $9(100.0)$ & \\
\hline \multicolumn{3}{|l|}{ Diabetes mellitus } \\
\hline Yes & $0(0.0)$ & \\
\hline No & $9(100.0)$ & \\
\hline \multicolumn{3}{|l|}{ Fever } \\
\hline Yes & $2(22.2)$ & \\
\hline No & $7(77.8)$ & \\
\hline \multicolumn{3}{|l|}{ Cough } \\
\hline Yes & $2(22.2)$ & \\
\hline No & $7(77.8)$ & \\
\hline \multicolumn{3}{|l|}{ Dyspnea } \\
\hline Yes & $2(22.2)$ & \\
\hline No & $7(77.8)$ & \\
\hline \multicolumn{3}{|l|}{ Myalgia } \\
\hline Yes & $0(0.0)$ & \\
\hline No & $9(100.0)$ & \\
\hline \multicolumn{3}{|l|}{ Sore throat } \\
\hline Yes & $0(0.0)$ & \\
\hline No & $9(100.0)$ & \\
\hline \multicolumn{3}{|l|}{ Diarrhea } \\
\hline Yes & $0(0.0)$ & \\
\hline No & $9(100.0)$ & \\
\hline \multicolumn{3}{|c|}{ Leukocytes (thousands $/ \mu \mathrm{L}$ ) } \\
\hline $4.500-11.000$ & $5(55.6)$ & $10.411 \pm 2.02$ \\
\hline$>11.000$ & $4(44.4)$ & \\
\hline \multicolumn{3}{|c|}{ Lymphocytes (\%) } \\
\hline$<22$ & $8(88.9)$ & $1612+462$ \\
\hline $22-44$ & $1(11.1)$ & $16.43 \pm 4.62$ \\
\hline$>44$ & $0(0.0)$ & \\
\hline \multicolumn{3}{|l|}{ Neutrophils (\%) } \\
\hline $55-79$ & $6(66.7)$ & $77.08 \pm 4.63$ \\
\hline$>80$ & $3(33.3)$ & \\
\hline NLR & & $5.016 \pm 1.676$ \\
\hline$<5.8$ & $7(77.8)$ & \\
\hline$\geq 5.8$ & $2(22.2)$ & \\
\hline
\end{tabular}


Table 1 (continued).

\begin{tabular}{|c|c|c|}
\hline Variable & n (\%) & Mean \\
\hline \multicolumn{3}{|l|}{ Hemoglobin (g/dL) } \\
\hline$<10$ & $0(0.0)$ & $11.98 \pm 1.18$ \\
\hline$\geq 10$ & $9(100.0)$ & \\
\hline \multicolumn{3}{|l|}{ SGOT / SGPT } \\
\hline Normal & $8(88.9)$ & \\
\hline Abnormal & $1(11.1)$ & \\
\hline \multicolumn{3}{|l|}{ Platelets (thousands $/ \mu \mathrm{L}$ ) } \\
\hline$<150$ & $0(0.0)$ & $265.88 \pm 50.23$ \\
\hline$>150$ & $9(100.0)$ & \\
\hline \multicolumn{3}{|l|}{ Chest X-ray } \\
\hline Pneumonia & $2(22.2)$ & \\
\hline No Pneumonia & $7(77.8)$ & \\
\hline \multicolumn{3}{|l|}{ Rapid test } \\
\hline Positive & $8(88.9)$ & \\
\hline Negative & $1(11.1)$ & \\
\hline \multicolumn{3}{|c|}{ Maternal COVID-19 PCR swab } \\
\hline Positive & $3(33.3)$ & \\
\hline Negative & $6(66.7)$ & \\
\hline \multicolumn{3}{|l|}{ Infant delivery } \\
\hline Yes & $8(88.9)$ & \\
\hline No & $1(11.1)$ & \\
\hline \multicolumn{3}{|l|}{ Ventilator } \\
\hline Yes & $1(11.1)$ & \\
\hline No & $8(88.9)$ & \\
\hline \multicolumn{3}{|l|}{ Pulmonary edema } \\
\hline Yes & $1(11.1)$ & \\
\hline No & $8(88.9)$ & \\
\hline \multicolumn{3}{|l|}{ Renal failure } \\
\hline Yes & $0(0.0)$ & \\
\hline No & $9(100.0)$ & \\
\hline \multicolumn{3}{|l|}{ Heart } \\
\hline Yes & $0(0.0)$ & \\
\hline No & $9(100.0)$ & \\
\hline \multicolumn{3}{|l|}{ Maternal death } \\
\hline Death & $0(0.0)$ & \\
\hline No death & $9(100.0)$ & \\
\hline Infant birth weight (g) & & $2825 \pm 332.74$ \\
\hline$<2500$ & $0(0.0)$ & \\
\hline$\geq 2500$ & $8(88.9)$ & \\
\hline \multicolumn{3}{|l|}{ Newborn APGAR score } \\
\hline$<7$ & $0(0.0)$ & \\
\hline$\geq 7$ & $8(88.9)$ & \\
\hline \multicolumn{3}{|c|}{ Newborn with severe asphyxia } \\
\hline Yes & $0(0.0)$ & \\
\hline No & $8(88.9)$ & \\
\hline \multicolumn{3}{|l|}{ Infant death } \\
\hline Death & $0(0.0)$ & \\
\hline No death & $8(88.9)$ & \\
\hline \multicolumn{3}{|c|}{ Newborn COVID-19 PCR swab } \\
\hline Positive & $0(0.0)$ & \\
\hline Negative & $8(88.9)$ & \\
\hline
\end{tabular}

NLR: Neutrophil-to-lymphocyte ratio 
Table 2. Association between NLR and COVID-19 infection in pregnant women

\begin{tabular}{ccccc}
\hline & Confirmed group $(\mathbf{n}=\mathbf{1})$ & Control group $(\mathbf{n}=\mathbf{8})$ & PR (95\% CI) & p value \\
\hline NLR & & & & \\
$<5.8$ & $1(14.3)$ & $6(85.7)$ & $0.143(0.023-0.877)$ & 0.023 \\
$\geq 5.8$ & $2(100.0)$ & $0(0.0)$ & & \\
\hline
\end{tabular}

Notes: NLR: neutrophil-to-lymphocyte ratio; PR: prevalemce ratio; CI: confidence interval; *Significant at p $<0.05$

\section{DISCUSSION}

Our study results showed that the clinical picture of patients with COVID-19 infection during pregnancy was similar to that of adult non-pregnant women with COVID-19 infection, comprising fever, cough and dyspnea, whereas the symptoms of myalgia, malaise, sore throat, and diarrhea, were seldom found, as had previously been reported by Chen et al. ${ }^{(16)}$ Eight pregnant women in the present study underwent cesarean section, with obstetric indications of severe preeclampsia, history of previous cesarean sections, and fetal distress, while one case arrived at a gestational age of 31 weeks and was discharged without having undergone delivery and being in good condition without complications. Termination of pregnancy by cesarean section is in accordance with the protocol of the Indonesian Association of Obstetrics and Gynecology (POGI) thereby avoiding the risk of infection from the mother to the fetus through vaginal delivery. ${ }^{(17)}$ In the present study, fetal outcomes were good for all conditions, and did not require special nursing care. This proves that the postpartum condition of the infant was not affected by the mothers having been infected with COVID-19. This agrees with the study of Zaigham et al. ${ }^{(20)}$ who showed that the majority of pregnant women were infected with COVID-19 in the third trimester and was delivered by cesarean section, with no maternal deaths. In contrast, pregnant women infected with other earlier respiratory viruses, such as H1N1, were reported to be approximately 4-5 times more likely to develop severe disease compared with non-pregnant individuals in the general population. ${ }^{(21)}$
In our study an association was found between NLR values and swab test results in pregnant women with COVID-19 infection. However, differing results were obtained in the study of Yang et al. ${ }^{(18)}$ which showed that in the prenatal and postpartum periods there were no differences in NLR values. The latter study also states that routine blood tests were more suitable for screening of pregnant women with asymptomatic or mild COVID-19 infection, and may be used for screening of COVID-19 in pregnant women in areas of epidemic COVID19 infection.

The increased NLR in our study is in line with the findings in Spain by Pereira et al. ${ }^{(19)}$ who showed an increase in NLR in pregnant women with COVID-19 infection and a decrease in NLR upon improvement of the clinical condition. The study of Qin et al. ${ }^{(14)}$ also showed that patients with COVID-19 experienced an increase in the neutrophil count and a decrease in the lymphocyte count in the severe phase, suggesting the possibility of a critical condition and serious internal abnormalities in these patients.

The study by Luo et al. ${ }^{(23)}$ showed that NLR may be used as a sufficiently good inflammatory marker. From the pathophysiological point of view, neutrophils represent the nonspecific immune system that initiate the body responses to inflammation, whereas the lymphocytes represent the protective component against inflammation. The inflammatory condition will trigger hypersecretion of inflammatory cytokines, such as IL-6 and TNF- $\alpha$, resulting in a permanently high neutrophil count. In contrast, catecholamines, cortisol, and the increased proinflammatory mediators will bind to lymphocyte surface receptors and subsequently initiate 
apoptosis of the lymphocytes, thus causing lymphopenia. ${ }^{(24)}$ Similarly, the study of Yang et al. ${ }^{(18)}$ on COVID-19 also showed that NLR is significantly higher in the COVID-19 group, and that the increase in NLR may be considered as an independent marker of poor clinical outcome. There are several limitations in our study. Firstly, since this study was limited by its small sample size, therefore a number of considerations have to be taken when interpreting the findings. Secondly, for a number of patients in our study, the initial clinical diagnosis of patients under supervision (PDP) was confirmed with the rapid IgM specific antibody test. Although the reported sensitivity and specificity were relatively good, still the potential for the occurrence of selection bias has to be taken into consideration. This is due to the fact of a shortage of diagnostic equipment, so that not all patients could be directly subjected to the PCR swab test, to the fact that it took a long time for the swab test results to become available, and the fact that the limited supply of test reagents necessitated the inclusion of only those with clinical symptoms or a clinical diagnosis for serologic as well as swab testing, thus producing selection bias. Thirdly, samples such as placental tissues, amniotic fluid and cord blood were not collected for the COVID-19 test.

The results of the present study may be used as input for the early detection of cases of COVID-19 in pregnant women, by means of NLR, at a cut-off point of $\geq 5.8$.

There is still a need for further studies on pregnant women with COVID-19 and their fetuses. Suggestions for further studies consist of increasing the sample size and the study variables to be used in early detection or as predictors.

\section{CONCLUSIONS}

Pregnant women with NLR $<5.8$ have a 0.143 times lower risk for suffering from COVID-19 infection in comparison with pregnant women with NLR $\geq 5$.8. The NLR may be used as marker for early detection of cases of pregnant women with COVID-19 infection.

\section{CONFLICTS OF INTEREST}

The authors declare that there were no conflicts of interests in connection with the study, and the writing and publication of this article.

\section{ACKNOWLEDGMENTS}

The authors thank the Director of Dr. Moewardi Hospital Surakarta, for the opportunity to perform this study and collect the data.

\section{CONTRIBUTORS}

NWPA contributed to drafting of the manuscript, formulating the conceptual framework, and collecting and processing the research data. SS played a role in revising the article. All authors have read and approved the final manuscript.

\section{REFERENCES}

1. Dashraath P, Wong JLJ, Lim MXK, et al. Coronavirus disease 2019 (COVID-19) pandemic and pregnancy. Am J Obstet Gynecol 2020;222: 521-31. http://doi.org/10.1016/j.ajog. 2020.03.21.

2. Lapinsky SE. Acute respiratory failure in pregnancy. Obstet Med 2015;8:126-32. doi: $10.1177 / 1753495 X 15589223$.

3. Qiao J. What are the risks of COVID-19 infection in pregnant women? Lancet 2020;395:760-2. https://doi.org/10.1016/S0140-6736(20)30365-2.

4. Hantoushzadeh S, Shamshirsaz AA, Aleyasin A, et al. Maternal death due to COVID-19. Am J Obstet Gynecol 2020;20:30516-20. doi: 10.1016/ j.ajog.2020.04.030.

5. Mor G, Cardenas I, Abrahams V, Guller S. Inflammation and pregnancy: the role of the immune system at the implantation site. Ann N Y Acad Sci 2011;1221:80-7. doi: 10.1111/j.17496632.2010.05938.x.

6. Costela-Ruiz VJ, Illescas-Montes R, Puerta-Puerta JM, Ruiz C, Melguizo-Rodríguez L. SARS-CoV-2 infection: the role of cytokines in COVID-19 disease. Cytokine Growth Factor Rev 2020;20: 
30109-X. http://doi.org/10.1016/j.cytogfr.2020.06. 001.

7. Liu H, Wang LL, Zhao SJ, Kwak-Kim J, Mor G, Liao AH. Why are pregnant women susceptible to COVID-19? An immunological viewpoint. J Reprod Immunol 2020;139:103122. doi: 10.1016/ j.jri.2020.103122.

8. Hai L, Hu ZD. The clinical utility of neutrophil to lymphocyte ratio in pregnancy related complications: a mini-review. J Lab Precis Med 2020;5:1. doi: 10.21037/jlpm.2019.10.03.

9. Song CY, Xu J, He JQ, Lu YQ. Covid 19 early warning score: a multiparameter screening tool to identify highly suspected patients. medRxiv 2020;1-22. https://doi.org/10.1101/2020.03.05. 20031906.

10. Arif SK, Muchtar F. Buku pedoman penanganan pasien kritis covid 19. Makasar: Perhimpunan Dokter Anestesi dan Terapi Intensif (Perdatin); 2020.

11. Liu Y, Du X, Chen J, et al. Neutrophil-tolymphocyte ratio as an independent risk factor for mortality in hospitalized patients with COVID19. J Infect 2020;81:e6-e12. https://doi.org/ 10.1016/jinf.2020.04.002.

12. Channappanavar R, Perlman S. Pathogenic human coronavirus infections: causes and consequences of cytokine storm and immunopathology. Semin Immunopathol 2017;39: 529-39. https://doi.org/10.1007/s00281-017-0629$\mathrm{x}$

13. Min CK, Cheon S, Ha NY, et al. Comparative and kinetic analysis of viral shedding and immunological responses in MERS patients representing a broad spectrum of disease severity. Sci Rep 2016;6:25359. https://doi.org/10.1038/ srep25359.

14. Qin C, Zhou L, Hu Z, et al. Dysregulation of immune response in patients with coronavirus 2019 (COVID-19) in Wuhan, China. Clin Infect Dis 2020;ciaa248. https://doi.org/10.1093/cid/ciaa248

15. Lou M, Luo P, Tang R, et al. Relationship between neutrophil-lymphocyte ratio and insulin resistance in newly diagnosed type 2 diabetes mellitus patients. BMC Endocr Disord 2015;15:9.
16. Chen H, Guo J, Wang C, et al. Clinical characteristics and intrauterine vertical transmission. Lancet 2020;395: 809-15. https:// doi.org/10.1016/S0140-6736(20)30360-3.

17. Pokja Infeksi Saluran Reproduksi Perkumpulan Obstetri Dan Ginekologi Indonesia Tahun 2020 . Rekomendasi penanganan infeksi virus corona (COVID-19) pada maternal (hamil, bersalin dan nifas). Surabaya: POGI; 2020.

18. Yang H, Sun G, Tang F, et al. Clinical features and outcomes of pregnant women suspected of coronavirus disease 2019. J Infection 2020;81:e40 e4. https://doi.org/10.1016/j.jinf.2020.04.003.

19. Pereira A, Cruz-Melguizo S, Adrien M, Fuentes L, Marin E, Perez-Medina T. Clinical course of coronavirus disease-2019 in pregnancy. Acta Obstet Gynecol Scand 2020;99:839-47. https:// doi.org/10.1111/aogs.1392119.

20. Zaigham M, Andersson O. Maternal and perinatal outcomes with COVID-19: a systematic review of 108 pregnancies. Acta Obstet Gynecol Scand 2020;99:823-9. https://doi.org/10.1111/aogs.13867.

21. Cérbulo-VázquezA, Figueroa-Damián R, ArriagaPizano LA, et al. Pregnant women infected with pandemic H1N1pdm2009 influenza virus displayed overproduction of peripheral blood CD69+ lymphocytes and increased levels of serum cytokines. PLoS ONE 2014;9:e107900. doi: 10.1371/journal.pone.0107900.

22. Wang D, Hu B, Hu C, et al. Clinical characteristics of 138 hospitalized patients with 2019 novel coronavirus-infected pneumonia in Wuhan, China. JAMA 2020;323: 1061-69. http://doi.org/ 10.1001/jama.2020.1585.

23. Luo Y, Xie Y, Zhang W, et al. Combination of lymphocyte number and function in evaluating host immunity. Aging (Albany NY) 2019;11: 12685-707. doi: 10.18632/aging.102595.

24. Almeida MQ, Mendonca BB. Adrenal insufficiency and glucocorticoid use during the COVID-19 pandemic. Clinics. 2020;75:e2022. DOI: 10.6061/clinics/2020/e2022. 